\title{
Investigation of hydrodynamic behaviour of membranes using radiotracer techniques
}

\author{
A. Miskiewicz and G. Zakrzewska-Trznadel \\ Institute of Nuclear Chemistry and Technology, 03-195 Warsaw, Poland
}

\begin{abstract}
The aim of the work was to study membrane devices using short-lived radioisotopes like Ba- $137 \mathrm{~m}$ and Ga- 68 as tracers. These radioisotopes were obtained from radionuclide generators: Cs-137/Ba-137m and Ge-68/Ga-68. The first radionuclide, namely Ba- $137 \mathrm{~m}$ with a half-life of 2.55 minutes was applied as a liquid phase tracer for studying hydrodynamic conditions inside the membrane apparatus. The membrane module with ceramic membranes was tested by using Ba- $137 \mathrm{~m}$. The experiments showed that this radionuclide with a short half-life is a perfect tracer for liquid phase, whereas Ga-68 with longer half-life equal to 68 minutes was considered as a solid phase (bentonite) tracer. Ga-68 was used to gain more knowledge about the phenomena occurring in the membrane boundary layer. After kinetic studies of isotope adsorption into the carrier material, the growth rate of the deposit layer as well as deposit's thickness on the flat-sheet membrane were studied. The influence of such process parameters like pressure, linear velocity of liquid and feed concentration on formation of the bentonite layer on the membrane surface was studied.
\end{abstract}

\section{INTRODUCTION}

The study of processes proceeding inside the membrane apparatus is hindered because of the construction of membrane modules, which are closed and non-transparent systems. There are many well-developed methods used for investigation of phenomena taking place in membrane devices, however they have often fundamental restrictions. The optical methods such as Direct Visualization Above the Membrane (DOTM) or Direct Observation Through the Membrane (DVAM) as well as laser methods like laser triangulometry [1-3] require transparent membrane modules used in experiments or apparatus having windows made of glass. Other techniques like Small-Angle Neutron Scattering (SANS), Magnetic Resonance Imaging (MRI) or Electrical Impedance Spectroscopy (EIS) [4-6] are expensive and involve sophisticated equipment.

Tracer techniques, which are non-invasive methods, are the alternative for the study of processes proceeding inside the membrane apparatus. They do not require complicated equipment to be used and they are well developed and they have proven for studying many other apparatuses operating in chemical industry.

One of the main problems and restrictions that limit wide applications of membrane methods is membrane fouling resulting in continuous flux decline. This phenomenon can drastically decrease the economics of membrane processes, therefore requires minimisation or careful control. There are examples of the development of methods for online detection of membrane fouling by a residence time distribution (RTD) technique using non active tracers. Hadson et al. described the method based on determination of flow dispersion intensities from online RTD signals of $\mathrm{NaCl}$ that can be simply measured [7]. The systems reported in this paper were spiral wound RO membranes fouled with either $\mathrm{Mg}(\mathrm{OH})_{2}$ or $\mathrm{CaCO}_{3}$. The residence time distribution (RTD) curves were also determined by using non active tracer in order to observe the shell-side flow status in hollow fibre modules (HFMs) during the membrane extraction process [8]. Rector et al. studied the effects of membrane module porosity and rotational frequency on hydrodynamic conditions and intensity of mixing in the rotational membrane bioreactor (RMBR) [9]. Conventional tracer studies applying sodium bromide as a marker were conducted using three differing module packing densities to determine their effects on the residence time distribution (RTD) in the RMBR.

New substances, which can be used for tracer examinations are synthesized. One of them, the new biosynthetic tracer has been developed to characterize dynamics of membrane filtration systems for virus retention [10]. This new tracer was designed to be directly and quickly detected/quantified in the waters produced and was obtained by grafting enzymatic probes on the surface of an MS2 bacteriophage. However, radiolabelled compounds have advantages over non-active tracers due to very high sensitivity of detection, which gives the opportunity for using very low concentration of the tracer, as well as for remote detection of radiation through the layers of other materials present in the apparatus. Therefore, the material, which membrane module is made from is unrestricted. Radioisotopelabelled macromolecules were used for the first time to study concentration polarization by McDonogh et al. $[11,12]$. The accumulation of radio-labelled macromolecules on the membrane surface due to concentration polarization was detected as an increase in voltage by a scintillation detector. The detected signal was converted to a corresponding mass of the macromolecules above the membrane to monitor the development of concentration gradient and to observe concentration polarization phenomenon.

Radiotracers were used for studying the properties of liquid membranes. A.-L. Rollet et al., investigated the structure of sulfonated PolyImide (sPI) ionomer membrane via the transport properties of ions confined inside [13]. Transport coefficients of $\mathrm{N}\left(\mathrm{CH}_{3}\right)_{4}^{+}$and $\mathrm{Na}^{+}$ions were 
determined in this work by several techniques in order to get a range of time/space scale as wide as possible, and radiotracer technique was one of methods used in this study.

Radiotracer method was also applied in multicomponent diffusion studies of poly (perfluorosulfonated) ion-exchange membrane, Nafion-117 [14]. Two cations, having significantly different self-diffusivity and selectivity: $\mathrm{Na}^{+}$and $\mathrm{Cs}^{+}$were tested in this work. ${ }^{137} \mathrm{Cs}$ and ${ }^{22} \mathrm{Na}$ were used to follow the time dependent concentration of the competing ions in the membrane. Conductivity and selectivity of ion-exchange membranes (IEMs) were also studied by different means, including electrochemical impedance spectroscopy, Raman vibrational spectroscopy as well as radiotracer methods [15].

Denamganai et al. [16] revealed that the radiotracer technique can be used to follow desorption and exchange processes with vinyl4pyridine (V4P) and quaternary ammonium membranes (QAM) for the purpose of comparing the properties of these two types of membranes and to point out the deprotonation process in V4P membranes. Exchange capacities obtained with this technique were compared with those obtained by microanalysis titration of nitrogen from V4P exchange sites. With radiotracers the authors of the paper set up the new technique to determine the $\mathrm{pK}$ of these membranes.

The present paper reports the studies of different configurations of membrane devices using short-lived isotopes of $\mathrm{Ba}-137 \mathrm{~m}$ and $\mathrm{Ga}-68$ as the tracers. The first radionuclide, $\mathrm{Ba}-137 \mathrm{~m}$, was applied as the liquid phase marker to test hydrodynamic conditions inside the membrane apparatus. The second one, Ga-68 with longer half-life of 68 minutes was employed as a solid phase tracer in order to get information about the phenomena occurring in the membrane boundary layer.

\section{EXPERIMENTAL}

\subsection{Membranes}

\subsubsection{Tubular membrane module}

Radiotracer methodology was applied for examination of ultrafiltration process and studying hydrodynamics of UF modules. The tests with ${ }^{137 \mathrm{~m}} \mathrm{Ba}$ were carried out in the unit with cross-flow tubular UF membrane module (Fig. 1), which enabled to handle feed flows in the range of 0.1 to $0.5 \mathrm{~m}^{3} / \mathrm{h}$ at pressures of 1 to 3 bar. The system was equipped with a ceramic membrane, $0.1 \mu \mathrm{m}$ pore size, (Atech Innovations, $\mathrm{GmbH}$ ), having the following dimensions: length $-1 \mathrm{~m}$, inner diameter $-16 \mathrm{~mm}$, filtration area $-0.05 \mathrm{~m}^{2}$.

\subsubsection{Flat-sheet membrane apparatus}

The studies of the phenomena in the membrane boundary layer were carried out with the set-up equipped with the flat-sheet membrane shown in Figure 2. The experiments concerned evaluation of the cake-layer thickness and the rate of its development in situ. As a tracer ${ }^{68} \mathrm{Ga}$

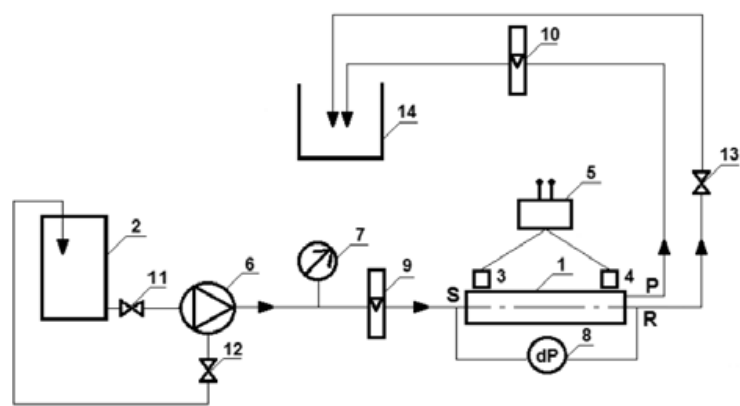

Figure 1. Scheme of installation for ultrafiltration experiments, 1 - membrane module, 2 - feed reservoir, 3, 4 - scintillation probes, 5 - radiometer, 6 - positive-displacement pump, 7 manometer, 8 - differential pressure transmitter, 9, 10 - flow meters, 11-13 - control valves, 14 - vessel for liquid wastes.

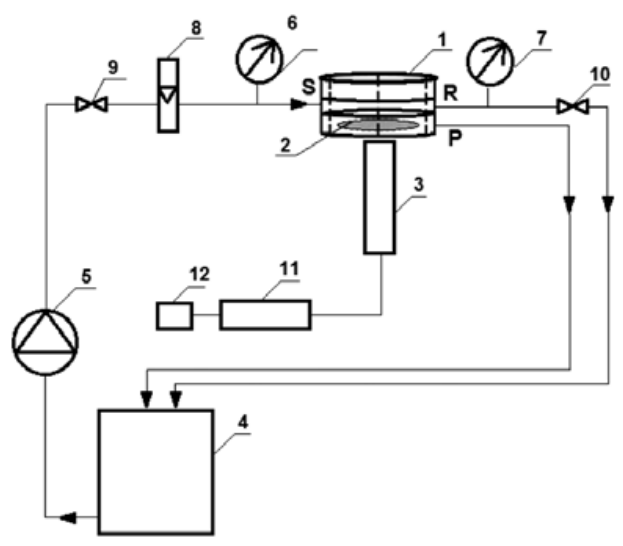

Figure 2. Scheme of the installation with the flat sheet membrane module, 1 - membrane module, 2 - membrane, 3 - scintillation probe, 4 - feed tank, 5 - positive-displacement pump, 6, 7 manometers, 8 - flow meter, 9, 10 - valves, 11 - radiometer, 12 - computer.

radioisotope was applied. The membrane made of PES, with $0.1 \mu \mathrm{m}$ pore size and filtration area of $0.002 \mathrm{~m}^{2}$ was used in the experiments.

\subsection{Preparation of radiotracers}

As a source of barium radiotracer the ${ }^{137} \mathrm{Cs} /{ }^{137 m} \mathrm{Ba}$ radioisotope generator delivered by the Centre of Radiochemistry and Nuclear Chemistry, INCT, with the initial activity equal $9.25 \mathrm{MBq}, \quad\left({ }^{137} \mathrm{Cs} \quad \tau_{1 / 2}=\right.$ $30.17 \mathrm{y},{ }^{137 \mathrm{~m}} \mathrm{Ba} \tau_{1 / 2}=2.55 \mathrm{~min}$.) was used. ${ }^{68} \mathrm{Ge} /{ }^{68} \mathrm{Ga}$ radioisotope generator (Spezial Chemikalien-Vertrieb, $A=55 \mathrm{MBq}$ ) was applied as a source of gallium radiotracer, $\left({ }^{68} \mathrm{Ge} \tau_{1 / 2}=271 \mathrm{~d},{ }^{68} \mathrm{Ga} \tau_{1 / 2}=67.7 \mathrm{~min}\right.$.). AR grade bentonite (Aldrich, No 285234) with average particle size, APS $=5.45 \mu \mathrm{m}$ was used in the studies to prepare water-bentonite suspension simulating process medium.

The first part of studies that concerned develop ment of the deposit on the membrane surface was examination of the kinetics of adsorption of ${ }^{68} \mathrm{Ga}$ isotope in the form of ${ }^{68} \mathrm{GaCl}_{3}$ on the carrier material, which was bentonite suspension in water. The stability of gallium adsorption on bentonite seeds was tested to obtain the 
Table 1. The influence of $\mathrm{pH}$ on ${ }^{68} \mathrm{Ga}$ adsorption on the bentonite.

\begin{tabular}{|c|c|c|c|}
\hline $\mathbf{p H}$ & $\mathbf{A}_{\mathbf{0}}, \mathbf{i m p . / s}$ & $\mathbf{A}_{\mathbf{f}}, \mathbf{i m p} . / \mathbf{s}$ & $\mathbf{D F}$ \\
\hline 2 & 3507.4 & 1.4 & 2532 \\
\hline 4 & 3688.2 & 6.6 & 560 \\
\hline 5 & 3819.4 & 7.9 & 484 \\
\hline 7 & 2814.6 & 10.7 & 262 \\
\hline 9 & 4177.9 & 33.9 & 123 \\
\hline
\end{tabular}

$\mathrm{A}_{0}$ - initial specific activity of bentonite suspension with ${ }^{68} \mathrm{GaCl}_{3}$, $\mathrm{A}_{f}$ - specific activity of solution after adsorption (after filtration), $\mathrm{DF}$ - decontamination factor $\left(\mathrm{A}_{0} / \mathrm{A}_{f}\right)$.

marker permanently bound with its carrier suspended in water to simulate suspension treated in membrane process.

\subsubsection{Influence of $\mathrm{pH}$ on ${ }^{68} \mathrm{Ga}$ adsorption on bentonite}

A few samples at different $\mathrm{pH}$ were prepared as follows: $1 \mathrm{~g}$ of bentonite (particle size $=5.45 \mu \mathrm{m}$ ) was mixed with $10 \mathrm{ml}$ of water and few drops of ${ }^{68} \mathrm{Ga}$ solution in the form of $\mathrm{GaCl}_{3}$ of the initial activity listed in Table 3 were added. The $\mathrm{pH}$ of the sample was adjusted by using $1 \mathrm{M} \mathrm{NaOH}$ or $1 \mathrm{M} \mathrm{HNO}_{3}$. The suspensions were mixed for 60 minutes and then centrifuged (for $3 \mathrm{~min}$. at $12000 \mathrm{rpm}$ ), then filtrated using syringe filters (NY, $0.2 \mu \mathrm{m})$. The specific activity of 2 ml-samples after filtration was measured using a gamma counter (LG-1B, Institute of Nuclear Chemistry and Technology, Poland). The results of experiments are collected in Table 1.

The experiments showed the $\mathrm{pH}$ range from 2 to 7 is suitable for ${ }^{68} \mathrm{Ga}$ radionuclide sorption on the bentonite samples. The decontamination factors obtained in this $\mathrm{pH}$ range were high enough, what indicates that ${ }^{68} \mathrm{Ga}$ was well adsorbed on bentonite. The highest rate of sorption was observed for $\mathrm{pH}$ equal 2 , however in the next experiments $\mathrm{pH}=5$ was applied because it was natural $\mathrm{pH}$ of bentonite suspension with addition of ${ }^{68} \mathrm{GaCl}_{3}$ used in experiments. In that case satisfactorily high decontamination factor $(\mathrm{DF}=484)$ was also obtained.

\subsubsection{Kinetics of ${ }^{68} \mathrm{Ga}$ sorption on bentonite}

The suspension of $10 \mathrm{~g}$ of bentonite in $100 \mathrm{ml}$ of water with a few drops of ${ }^{68} \mathrm{GaCl}_{3} \quad\left(\mathrm{~A}_{0}=1115 \mathrm{imp} . / \mathrm{s}\right)$ at $\mathrm{pH}=5$ was prepared and mixed. During the experiments the samples were periodically collected for activity measurements. The samples were centrifuged (for $2 \mathrm{~min}$. at $12000 \mathrm{rpm}$ ) and suspensions were filtrated using syringe filters (NY, $0.2 \mu \mathrm{m}$ ). The activity concentration of $2 \mathrm{ml}$ samples of filtrate was measured (Table 2) and efficiency of sorption expressed in terms of decontamination factor was determined.

The results of experiments have shown that sorption of radioactive gallium on bentonite proceeds quite fast; after 19 minutes ${ }^{68} \mathrm{Ga}$ was not detected in filtrate, what indicates that all gallium was adsorbed on bentonite.
Table 2. Kinetics of ${ }^{68} \mathrm{Ga}$ sorption on bentonite.

\begin{tabular}{|c|c|c|}
\hline Time of reaction, min. & $\mathbf{A}_{\mathbf{0}}$, imp./s & $\mathbf{A}_{\mathbf{f}}, \mathbf{i m p} . / \mathbf{s}$ \\
\hline 5 & 1189.1 & 4.0 \\
\hline 19 & 1228.8 & 0.5 \\
\hline 40 & 1244.9 & 0.0 \\
\hline
\end{tabular}

$\mathrm{A}_{f}$ - specific activity of the solution after sorption experiments (after filtration).

Table 3. Results of bentonite rinsing.

\begin{tabular}{|c|c|c|}
\hline $\begin{array}{c}\text { Number of } \\
\text { rinsing }\end{array}$ & $\begin{array}{c}\text { Activity of } \\
\text { suspension, } \\
\text { imp./s }\end{array}$ & $\begin{array}{c}\text { Activity of } \\
\text { filtrate, } \\
\text { imp./s }\end{array}$ \\
\hline 1 & 767.9 & 0 \\
\hline 2 & 757.2 & 0 \\
\hline 3 & 737.2 & 0 \\
\hline 4 & 816.3 & 0 \\
\hline
\end{tabular}

\subsubsection{Study of the stability of ${ }^{68} \mathrm{Ga}$ sorption}

To study of the stability of ${ }^{68} \mathrm{Ga}$ adsorption the suspension of $2 \mathrm{~g}$ of bentonite in $20 \mathrm{ml}$ of water with a few drops of $\mathrm{GaCl}_{3}\left(\mathrm{~A}_{0}=1115 \mathrm{imp} . / \mathrm{s}\right)$ at $\mathrm{pH}=5$ was prepared and mixed for 40 minutes. Filtrated bentonite was rinsed using a few portions of water for verification of sorption stability. Results are presented in Table 3 , which shows that ${ }^{68} \mathrm{Ga}$ was permanently adsorbed on bentonite and was not rinsed off even for a long time of shaking (100 min.). Thereby, ${ }^{68} \mathrm{Ga}$ in the form of ${ }^{68} \mathrm{GaCl}_{3}$ can be used as the solid phase tracer in the experiments.

After the preliminary tests, the rate of formation of deposit layer and its thickness was determined with bentonite suspension labelled with ${ }^{68} \mathrm{Ga}$ radiotracer. Results of the experiments are illustrated in Figures 6-8 and discussed later.

\subsection{Radiotracer experiments}

\subsubsection{Study of hydrodynamic behaviour of tubular membrane}

The pulse injection was applied to study hydrodynamic behaviour of the membranes. The portion of $1 \mathrm{ml}$ of barium tracer in the form of ${ }^{137 m} \mathrm{BaCl}_{2}$ was injected at the inlet of the apparatus with tubular membrane (Fig. 1) with the syringe and the response (change of the activity in time) was monitored at its outlet. Two scintillation probes, SSI1 type $(3,4)$, were placed at the inlet of the feed and at the outlet of the retentate, respectively. The change of radioactivity of the tracer during experiments was monitored with the Radiometer, (INCT, Poland) FIR-1 type (5). The step of time discretization was $0.125 \mathrm{~s}$ per channel. Data transmission to the computer was carried out with the serial port of the COM type and the RS232 wire connection, under the Windows 9x system applying the HyperTerminal program. The recorded experimental results, i.e. outlet radioactivity of ${ }^{137 \mathrm{~m}} \mathrm{Ba}$ in the solution versus time $\mathrm{C}(\mathrm{t})$ were transmitted to the Matlab 7.01 
Table 4. The results of performed experiments using ${ }^{137 m} \mathrm{Ba}$ as water phase tracer.

\begin{tabular}{|c|c|c|c|c|c|}
\hline No & $\mathbf{p}, \mathbf{b a r}$ & $\mathbf{Q}_{\mathbf{R}}, \mathbf{l} / \mathbf{h}$ & $\mathbf{T}_{\mathbf{t}}, \mathbf{s}$ & $\mathbf{T}_{\mathbf{m}}, \mathbf{s}$ & $\mathbf{f}_{\mathbf{o}} \%$ \\
\hline I & 1 & 70 & 7.2 & 6.31 & 20 \\
\hline II & 3 & 170 & 3.6 & 4.1 & 17 \\
\hline III & 3 & 264 & 2.4 & 2.46 & 8.6 \\
\hline IV & 3 & 364 & 1.8 & 1.93 & 5.2 \\
\hline V & 3 & 464 & 1.44 & 1.53 & 4.9 \\
\hline
\end{tabular}

$\mathrm{T}_{\mathrm{t}}$ - theoretical residence time,

$\mathrm{T}_{\mathrm{m}}-$ mean residence time,

$\mathrm{f}_{0}$ - objective function.

Table 5. Results of experiments, ${ }^{137 \mathrm{~m}} \mathrm{Ba}$ as a tracer.

\begin{tabular}{|c|c|c|c|c|c|c|c|c|}
\hline No & $\begin{array}{c}\mathbf{T}_{\mathbf{m}} \\
\mathbf{s}\end{array}$ & vard & $\begin{array}{c}\tau_{\mathbf{1}} \\
\mathbf{s}\end{array}$ & $\mathbf{P e}_{\mathbf{1}}$ & $\begin{array}{c}\tau_{\mathbf{2}} \\
\mathbf{s}\end{array}$ & $\mathbf{P e}_{\mathbf{2}}$ & $\begin{array}{c}\mathbf{D}_{\mathbf{1}} \\
\mathbf{c m}^{2} \mathbf{s}\end{array}$ & $\begin{array}{c}\mathbf{D}_{\mathbf{2}} \\
\mathbf{c m}^{2} \mathbf{s}\end{array}$ \\
\hline I & 6.3 & 0.48 & 3.7 & 158 & 3.0 & 0.7 & 0.04 & 0.05 \\
\hline II & 4.1 & 0.31 & 2.5 & 92 & 0.3 & 0.4 & 0.10 & 0.26 \\
\hline III & 2.5 & 0.34 & 1.4 & 27 & 0.4 & 0.9 & 0.54 & 0.60 \\
\hline IV & 1.9 & 0.33 & 1.2 & 60 & 0.3 & 0.8 & 0.33 & 0.42 \\
\hline V & 1.5 & 0.26 & 1.3 & 8.4 & 0.2 & 1.2 & 3.07 & 2.56 \\
\hline
\end{tabular}

vard - dimensional variance of mean residence time.

program as the input data for further processing (Tables 4 and 5).

\subsubsection{Study of deposit development on the membrane surface}

After preparatory stage, the growth rate of the deposit layer as well as its thickness on the flat-sheet membrane was studied. Radiolabelled bentonite suspension was introduced into examined system (Fig. 2) and the rate of deposit development on the membrane surface during filtration, as a change of tracer radioactivity, was monitored by means of the collimated scintillation probe (3) placed under the membrane module. The change of radioactivity during experiments was monitored with the radiometer (11), the step of time discretization was $10 \mathrm{~s}$ per channel.

The influence of such process parameters like pressure, linear velocity and feed concentration on formation of the bentonite layer on the membrane surface was studied. For each experiment the new membrane was used to keep the same filtration conditions for all performed experiments.

\section{DATA ANALYSIS AND RESULTS}

On the basis of experiments modelling of hydrodynamic conditions by RTD methodology using ${ }^{137} \mathrm{ma}$ as the water phase tracer was performed. In general, the selection of the models of the liquid phase flow and the determination of parameters from tracer studies is based on analyses of impulse response functions $E(t)$, which are the RTDs obtained from a tracer input to the system as $\delta$-Dirac function (instantaneouzs injection). Because of small permeate/retentate flow ratio (about 5\%) the conception of one dimensional, axial-dispersion flow
A)

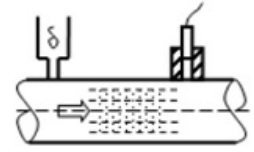

B)

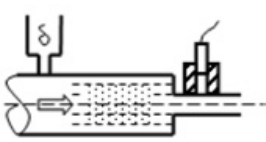

Figure 3. The scheme of axial dispersion models applied for modelling of chemical reactors a) open-open channel system, b) open-closed system.

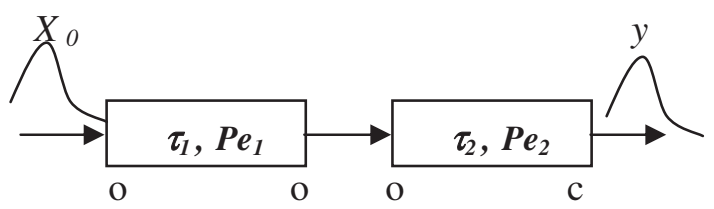

Figure 4. The scheme of the model applied for examined apparatus: two dispersion modules connected in series; the first with open-open channel boundary conditions, the second - openclosed channel.

models has been considered. Depending on actual conditions and apparatus configuration the boundary conditions applied in relation to axial dispersion models can be open-open, open-closed (semi closed) and closedclosed (fully closed) channel type (Fig. 3). In case of the installation under investigations a combination of two onedimensional axial dispersion models connected in series was proposed (Fig. 4).

Axial dispersion models are suitable for description of unaxial flows and deviations from the ideal plug flow due to dispersion in the flow direction. The intensity of this dispersion is proportional to the $D$ coefficient of axial dispersion, which corresponds to the turbulent diffusivity in turbulent flow and to effective dispersion in laminar flow. Relation of the convection mass transfer rate to the dispersive mass transfer rate is expressed as the Peclet number. The axial dispersion models are frequently applied not only for description of RTD in turbulent flows in pipes, but also for modelling of fluidized beds, packed beds, flotation columns, etc. [17].

While modeling residence time distribution data, if the input function is not an impulse (Dirac's Delta function), the experimental output is fitted with model simulated output. The model simulated output is obtained by convoluting experimental response of the inlet probe with model equation for impulse input $h_{m}(t)$. Model simulated output $\mathrm{y}_{m}(t)$ is given by $[18,19]$ :

$$
y_{m}(\mathrm{t})=\int_{0}^{t} X_{0}(z) h_{m}(t-z) d z
$$

Where $X_{0}$ is the input function and $h_{m}$ is the impulse response.

For the proposed model the model equation for the impulse input can be expressed as a function:

$$
h_{m}(t)=\int_{0}^{t} h_{1}(u) h_{2}(t-u) d u
$$




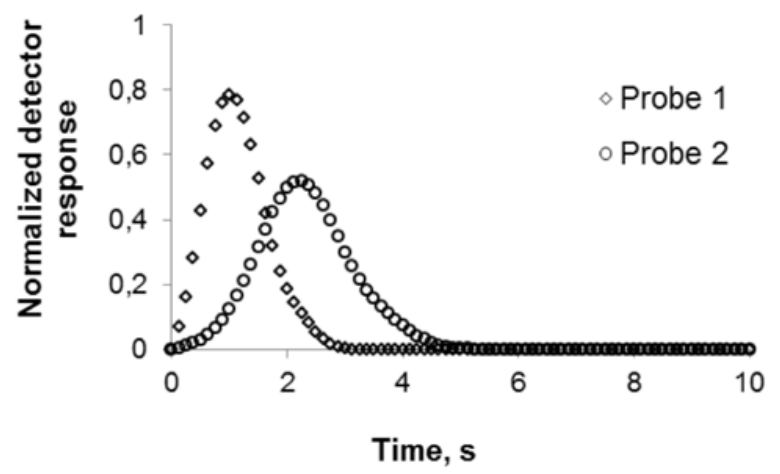

Figure 5a. Typical detector response signals obtained by injection a pulse of ${ }^{137 \mathrm{~m}} \mathrm{BaCl}_{2}$ solution.

where $h_{1}, h_{2}$ are impulse responses for constituent models expressed like below:

$$
\begin{aligned}
& h_{1}(t)=\frac{1}{\tau_{1}} \sqrt{\frac{P e_{1}}{4 \pi\left(\frac{t}{\tau_{1}}\right)}} \exp \left[\frac{-P e_{1}\left(1-\left(t / \tau_{1}\right)\right)^{2}}{4 \pi\left(t / \tau_{1}\right)}\right] \\
& h_{2}(t)=\frac{1}{\tau_{2}} \sqrt{\frac{P e_{2}}{4 \pi\left(\frac{t}{\tau_{2}}\right)^{3}}} \exp \left[\frac{-P e_{2}\left(1-\left(t / \tau_{2}\right)\right)^{2}}{4 \pi\left(t / \tau_{2}\right)}\right]
\end{aligned}
$$

where $\tau_{1}, \tau_{2}$ are the mean residence time constants for models and $P e_{1}, P e_{2}-$ Peclet numbers.

The theoretical residence time of the particle in the apparatus can be calculated as a ratio of the length of the apparatus $L[\mathrm{~m}]$ and linear velocity $u\left[\mathrm{~ms}^{-1}\right]$

$$
t_{t}=L / u
$$

or as a ratio of the volume of the apparatus $V$ and volume flow rate $Q_{R}$ :

$$
t_{t}=V / Q_{R}
$$

Parameters of the model: $\tau_{1}, P e_{1}, \tau_{2}$ and $P e_{2}$ were calculated by use of Hook-Jeeves method minimising the objective function $\left(f_{o}\right)$, which was expressed as follows:

$$
\operatorname{Min}\left(\frac{\sum_{i=1}^{m}\left|y\left(t_{i}\right)-y_{m}\left(t_{i}\right)\right| \Delta t_{i}}{\sum_{i=1}^{m} y\left(t_{i}\right) \Delta t_{i}}\right)
$$

where $\mathrm{y}$ is the measured detector response at the outlet.

\section{DISCUSSION}

Typical pulse and response curves for the system with tubular ceramic membrane are shown in Figure 5. Analysis of the results showed that good correlation was found between the experimental data and predicted models, (Table 4). In all cases low values of objective functions $\left(f_{o}\right)$ indicating appropriate model selection, were obtained.

Figure 5b shows a comparison of experimental and model simulated detector responses corresponding to the optimal model parameters. The model simulated curve is in a good agreement with experimental one.

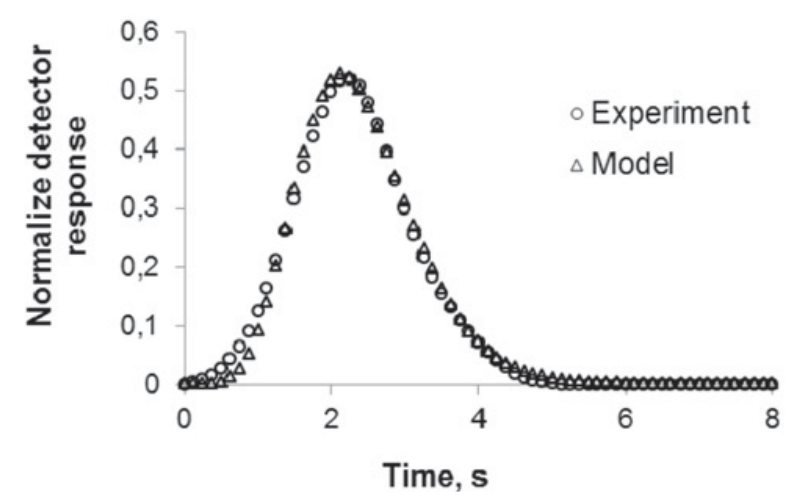

Figure 5b. Experimental and model simulated detector responses for optimal model parameters.

In all cases the experimental $\mathrm{T}_{\mathrm{m}}$ was higher than residence time calculated theoretically, what may suggest sorption of the tracer inside the apparatus. Only in case of experiment performed under lower transmembrane pressure and the lowest feed flow rate experimental $\mathrm{T}_{m}$ was lower than calculated theoretically $\left(\mathrm{T}_{t}\right)$ which may indicate the presence of dead zones in the apparatus under these conditions.

The parameters, which describe dynamics of the liquid in the membrane module (Pe, vard) were calculated from experiments and collected in Table 5. As can be observed, increase of feed flow rate caused generally decline of $\mathrm{Pe}_{1}$ and $\mathrm{Pe}_{2}$ numbers for the second part of the model with open-closed boundary conditions but the influence was not significant. The coefficients $\mathrm{D}_{1}$ and $\mathrm{D}_{2}$ shown in Table 5 in general have small values, which correspond to low axial dispersion in the system under investigation.

As experiments showed ${ }^{137 \mathrm{~m}} \mathrm{Ba}$ radionuclide from the generator can be used as a tracer for testing the membrane apparatus hydrodynamics. The short half-life of the radionuclide enables to carry out the subsequent experiments in a small-volume apparatus in relatively short time.

The tracer methods supported by modelling can be applied for the study of hydrodynamic conditions in the membrane installations. It allows to pick up all instabilities and regions of more intense axial mixing. This knowledge is helpful for design of equipment that allow minimising the phenomena like membrane blocking, which disturb their proper operation. Such knowledge enables to handle sufficient productivity of the membrane systems.

The results of experiments performed with the system with flat-sheet membrane showed a strong reduction of the deposit thickness with decrease of concentration of the suspension, which is shown in Figure 6. The influence of retentate flow rate in the range under investigation was negative and less significant (Fig. 7). However, the influence of transmembrane pressure on the deposit thickness was rather moderate (Fig. 8).

High rate of deposit formation in the beginning of filtration process as well as fast achievement of steady state (plateau) was observed for higher retentate flow rate. The similar behaviour was noticed in the case of filtration of the least concentrated suspensions in relation to the treatment of more concentrated medium: high 


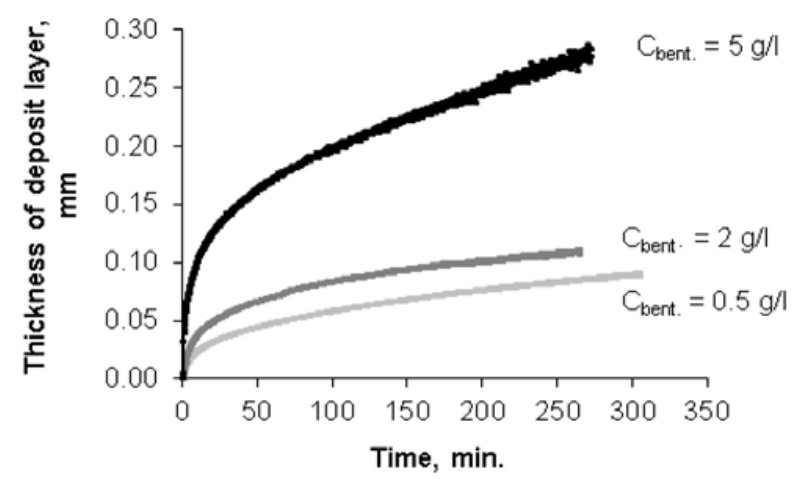

Figure 6. Comparison of the thickness of deposit layer depending on concentration of filtrated suspension; $\mathrm{p}=1.5$ bar, $v=$ $0.005 \mathrm{~m} / \mathrm{s}$, bentonite APS $=5.45 \mu \mathrm{m}$.

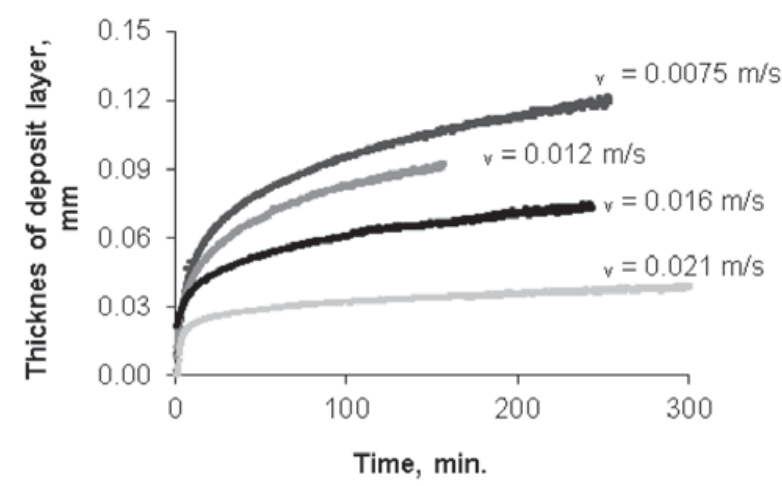

Figure 7. Comparison of deposit layer thickness depending on linear velocity of feed solution above the membrane; $p=3$ bar, $\mathrm{C}_{\text {bent. }}=2 \mathrm{~g} / \mathrm{l}$, bentonite APS $=5.45 \mu \mathrm{m}$.

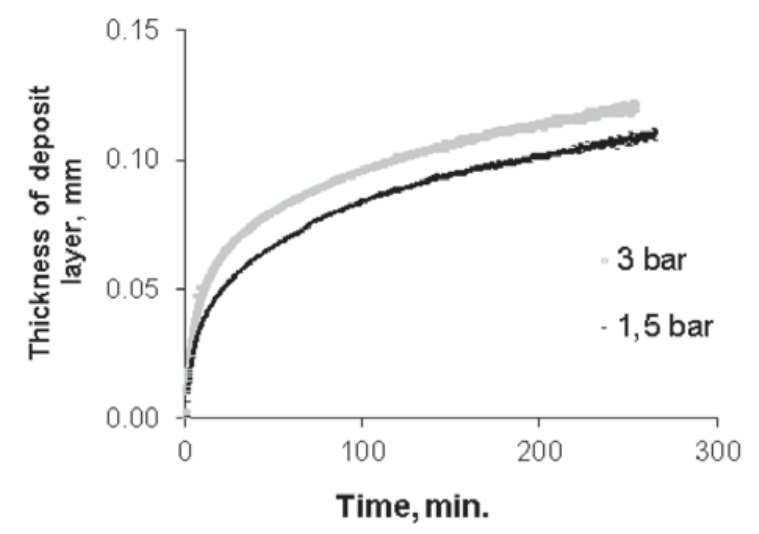

Figure 8. Comparison of the thickness of deposit layer depending on applied transmembrane pressure; $\mathrm{C}_{\text {bent. }}=2 \mathrm{~g} / \mathrm{l}$, $v=0.0075 \mathrm{~m} / \mathrm{s}$, bentonite APS $=5.45 \mu \mathrm{m}$.

rate of deposit formation was observed during the whole experiment (about $4 \mathrm{~h}$ ).

\section{CONCLUSIONS}

Elaborated radiotracer techniques can be useful for membrane processes control to prevent the membrane fouling and permeate flux decline in membrane filtration apparatuses.

The experiments, in which ${ }^{137 \mathrm{~m}} \mathrm{Ba}$ was applied showed that the radionuclide with a short half-life is an appropriate tracer of the liquid phase. It can be successfully used for examination of the membrane modules with a short residence time of the media in the apparatus. Moreover, the application of such a radiotracer does not result in long-lasting contamination of the examined equipment. The study of fluid flow dynamics in membrane filtration modules and full understanding of the phenomena in the boundary layer may help in apparatus design and operation.

The tracer method with application of ${ }^{68} \mathrm{Ga}$, which is a short-lived radionuclide, as well, has proved as a tool for the study of kinetics of the particle deposition and layer formation on the membrane surface. Thereby, elaborated techniques can be useful for membrane processes control to prevent the membrane fouling.

Supportive tools like radiotracer techniques are very helpful in scientific studies, as well as in common, industrial practice.

The studies were supported by the POIG project No. 01.01.0214-094-09-00 "Analysis of the possibility of uranium supply from indigenous resources" and by the Strategic Research Program "Technologies for the development of safe nuclear power", research task No. 4: "Development of techniques and technologies in support of spent fuel and radioactive waste management".

\section{References}

[1] H. Li, A.G. Fane, H.G.L. Coster, S. Vigneswaran, J. Membr. Sci. 149, 83-97 (1998)

[2] W. Mores, R.H. Davis, J. Membr. Sci. 189, 217-230 (2001)

[3] J. Altmann, S. Ripperger, J. Membr. Sci. 124, 119-128 (1997)

[4] T.J. Su, J.R. Lu, Z.F. Cui, R.K. Thomas, R.K. Heenan, Langmuir 14, 5517-5520 (1998)

[5] S. Yao, M. Costello, A.G. Fane, J. M. Pope, J. Membr. Sci. 99, 207-216 (1995)

[6] T. C. Chilcott, M. Chan, L. Gaedt, T. Nantawisarakul, A.G. Fane, H.G.L. Coster, J. Membr. Sci. 195, 153-167 (2002)

[7] D. Hasson, A. Drak, C. Komlos, Q. Yang, R. Semiat, Desalination 204, 132-144 (2007)

[8] Y. Wang, F. Chen, Y. Wang, G. Luo, Y. Dai, J. Membr. Sci. 216, 81-93 (2003)

[9] T.J. Rector, J.L. Garland, S.O. Starr, J. Membr. Sci. 278, 144-150 (2006)

[10] L. Soussan, C. Guigui, S. Alfenore, S. Mathe, C. Cabassud, Anal. Chim. Acta 690, 199-208 (2011)

[11] R.M. McDonogh, H. Bauser, N. Stroh, D.H. Chmiel, Chem. Eng. Sci. 47 (1), 271-279 (1992)

[12] R.M. McDonogh, H. Bauser, N. Stroh, U. Grauschopf, J. Membr. Sci. 104, 51-63 (1995) 
[13] A.L. Rollet, J.F. Blachot, A. Delville, O. Diat, A. Guillermo, P. Porion, L. Rubatat, G. Gebel, Eur. Phys. J. E 12, s01, 030 (2003)

[14] S. Sodaye, Ch. A.A. Goswami, J. Membr. Sci. 314, 221-225 (2008)

[15] G. Pourcelly, Desalination 147, 359-361 (2002)

[16] J. Denamganai, F. Schue, J. Sledz, J. Molenat, Eur. Polym. J. 31, 11, 1067-1074 (1995)
[17] Radiotracer Applications in Industry - a Guidebook, International Atomic Energy Agency (2004), Technical Reports No. 423, Vienna

[18] O. Levenspiel, Chemical Reaction Engineering, $2^{\text {nd }}$ Edition, New York: Wiley (1996)

[19] Guidebook on Radioisotope Tracers in Industry International Atomic Energy Agency (1990), Technical Report No. 316, Vienna 